\title{
Influence of the crystalline structure of cellulose on the production of ethanol from lignocellulose biomass
}

\author{
Małgorzata Smuga-Kogut ${ }^{*}$, Kazimiera Zgórska ${ }^{1}$, and Daria Szymanowska-Powałowska ${ }^{2}$ \\ ${ }^{1}$ Department of Biochemistry and Biotechnology, Koszalin University of Technology, Racławicka 15-17, 75-620 Koszalin, Poland \\ ${ }^{2}$ Department of Biotechnology and Food Microbiology, University of Life Science in Poznań, Wojska Polskiego 48, \\ 60-627 Poznań, Poland
}

Received March 2, 2015; accepted November 26, 2015

\begin{abstract}
A b s t r a c t. In recent years, much attention has been devoted to the possibility of using lignocellulosic biomass for energy. Bioethanol is a promising substitute for conventional fossil fuels and can be produced from straw and wood biomass. Therefore, the aim of this paper was to investigate the effect of 1-ethyl-3-methylimidazolium pretreatment on the structure of cellulose and the acquisition of reducing sugars and bioethanol from cellulosic materials. Material used in the study was rye straw and microcrystalline cellulose subjected to ionic liquid 1-ethyl3-methylimidazolium pretreatment. The morphology of cellulose fibres in rye straw and microcrystalline cellulose was imaged prior to and after ionic liquid pretreatment. Solutions of ionic liquid-treated and untreated cellulosic materials were subjected to enzymatic hydrolysis in order to obtain reducing sugars, which constituted a substrate for alcoholic fermentation. An influence of the ionic liquid on the cellulose structure, accumulation of reducing sugars in the process of hydrolysis of this material, and an increase in ethanol amount after fermentation was observed. The ionic liquid did not affect cellulolytic enzymes negatively and did not inhibit yeast activity. The amount of reducing sugars and ethyl alcohol was higher in samples purified with 1-ethyl-3-methylimidazolium acetate. A change in the supramolecular structure of cellulose induced by the ionic liquid was also observed.

$\mathrm{K}$ e y w o r d s: cellulose, ionic liquid, ethanol, reducing sugars, crystalline structure
\end{abstract}

\section{INTRODUCTION}

In recent years, there has been an increased interest in the production of bioethanol from renewable sources like sugar materials, cassava (Han et al., 2011), cashew apple juice (Neelakandan and Usharani, 2009), sorghum juice (Wang et al., 2011), bagasse, straw (Cheng and Timilsina, 2011), and wood biomass (McKendry, 2002), and bread-

\footnotetext{
*Corresponding author e-mail: malgorzata.smuga-kogut@tu.koszalin.pl
}

fruit starch (Betiku and Taiwo Abiola, 2015). In order to reduce dependency on fossil fuels and decrease the environmental pollution, it is necessary to search for alternative fuels. Biofuels - solid, liquid, or gaseous - are currently the only direct substitute for fossil fuels available on a significant scale (Gąsiorek and Wilk, 2011).

Lignocellulose is the main structural element of cell walls in many plants. The lignocellulose complex consists of three components: cellulose, hemicellulose, and lignin. The proportion of each fraction is dependent on the type of raw material. All these compounds are closely related to each other by covalent and hydrogen bonds. Lignocellulose biomass is most commonly used for production of renewable energy eg bioethanol. Ethyl alcohol can be produced from cellulose after decomposition of simple sugars (Sathitsuksanoh et al., 2012). Lignocellulose must undergo complicated pretreatment prior to alcoholic fermentation, which involves removal of lignin (non-saccharide fraction) and hydrolysis of cellulose (Szymanowska-Powałowska et al., 2014).

Cellulose is the most abundant organic material on earth and can be found in terrestrial plants, algae, and waste materials (agricultural waste and newspapers) (Pulidindi et al., 2014). The chemical structure of cellulose is composed of linear chain molecules, in which $\beta$-D-glucose units linked with 1,4-glycosidic bonds constitute repeating residues. Cellulose chains are linked with bonds and van der Waals forces, forming elementary fibrils (Li et al., 2010). Cellulose contains two types of regions. The first type, in which the cellulose chains are arranged in parallel and form a crystalline structure, and the second type, which forms

(C) 2016 Institute of Agrophysics, Polish Academy of Sciences 
amorphous groups, wherein the bonds are arranged irregularly. The degree of crystallinity of cellulose depends on the origin and its acquisition source (Bučko et al., 2012). The crystallinity index of cellulose ranges from $0 \%$ for amorphous cellulose to almost $100 \%$ for natural cellulose obtained from Valoniamacrophysa algal cells. The ratio between the crystalline and the amorphous fractions is of great importance for the availability of amorphous regions for different reagents, and has a significant impact on the physicochemical properties of the fibre. Long macromolecules of cellulose protruding from the surface of the cellulose crystallites form a so-called lattice fringe, allowing formation of associations between cellulose and non-cellulosic components of the cell wall (Surmiński, 2006).

Depolymerization of cellulose and its further decomposition, known as degradation, may occur as a result of hydrolysis, oxidation, and the enzymatic action of microorganisms (fungi, bacteria). It may also be thermal, photochemical, and radiation decomposition caused by the action of ultrasounds. Hydrolysis of cellulose occurs in the presence of acid solutions with different concentrations. Strong hydrolytic activity is referred to sulfuric, hydrochloric, and nitric acids. Hydrolytic enzymes secreted by fungi form Basidiomycetes also induce decomposition of cellulose and other carbohydrates (Lutomski, 2002).

Among new methods of chemical pretreatment, the use of ionic liquids is considered. Ionic liquid (IL) pretreatment of lignocellulosic materials has provided a new technical tool to improve lignocellulosic ethanol production (Zhu et $a l .$, 2013). The ionic liquid is also called a 'green solvent' and is a very good catalyst of the enzymatic hydrolysis reaction. It increases the amount of amorphous sites of treated cellulose, does not inhibit the enzymatic hydrolysis, separates lignin from cellulose, and can be reused in subsequent pretreatment processes (Brandt et al., 2012). Ionic liquids together with water, perfuoroalkanes, compounds in the supercritical state, and compounds from biorenewable sources (bioethanol, bioesters), are in the group of the most commonly used solvents (Shill et al., 2010). In many cases, they substitute previously used conventional molar solvents.

Cellulose can be well dissolved in ionic liquids (even at a concentration of solutions equal to $30 \%$ ). Solutions of ionic liquids and cellulose exhibit high viscosity and transparency, and after addition of small quantities of water, acetone, or ethyl alcohol, cellulose is precipitated from the solution. This mechanism can be exploited during isolation of cellulose from lignocellulose materials. The solvent does not react with cellulose, does not shorten the polymerized chain, and may be recovered and reused after the process (Surma-Ślusarska and Danielewicz, 2012).

The objective of the study was to investigate the effect of 1-ethyl-3-methylimidazolium acetate pretreatment on the structure of cellulose, and the acquisition of reducing sugars and bioethanol from cellulosic materials.

\section{MATERIALS AND METHODS}

Rye straw subjected to prior grinding in a colloidal mill and microcrystalline cellulose PH-101 from Sigma Aldrich constituted the material used in the study. The properties of rye straw were evaluated, for which Klason lignin, cellulose, and dry weight were determined (Krutul, 2002).

For the pretreatment of cellulosic materials, an ionic liquid 1-ethyl-3-methylimidazolium acetate from Sigma Aldrich was used. At room temperature, it is a solid with a relative density of $1.03 \mathrm{~g} \mathrm{~cm}^{3}$ at $25^{\circ} \mathrm{C}, \mathrm{pH}$ equal to 5.4 , and a melting point above $30^{\circ} \mathrm{C}$.

In the pretreatment, each $100 \mathrm{~g}$ of rye straw and microcrystalline cellulose dissolved in $100 \mathrm{~cm}^{3}$ of 1-ethyl3-methylimidazolium acetate were used. The sample was then heated at $120^{\circ} \mathrm{C}$ in a fermenter for $2 \mathrm{~h}$. The material with the ionic liquid was cooled to ambient temperature and $100 \mathrm{~cm}^{3}$ of deionized water was added to precipitate the cellulose and hemicellulose from the ionic liquid. The samples were mixed for approximately $30 \mathrm{~min}$. At this time, 1-ethyl-3-methylimidazolium acetate was transferred into the aqueous phase. The solution was decanted in order to obtain cellulose fibres linked with lignin and hemicellulose to a lesser extent. The process of rinsing with water and mixing was repeated three times, until complete removal of the ionic liquid. In the last stage, the precipitate was washed

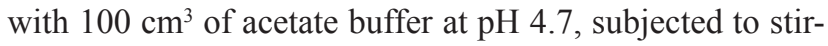
ring for approximately $15 \mathrm{~min}$, and decanted.

The morphology of cellulose fibres in the rye straw samples and microcrystalline cellulose after the ionic liquid pretreatment and prior to this treatment was imaged by an FEI Quanta 200 Mark 2 scanning electron microscope.

The solutions of the cellulosic material from rye straw and microcrystalline cellulose were subjected to enzymatic hydrolysis with the use of two types of enzyme preparations: cellulase from Trichoderma reesei ATCC 26921 (Sigma Aldrich, 7 FPU g ${ }^{-1}$ d.m. materials) and cellobiase Novozym 188 (Aspergillus niger, $30 \mathrm{CBU} \mathrm{g}^{-1} \mathrm{~d} . \mathrm{m}$. material). The process of cellulose degradation lasted $72 \mathrm{~h}$ at $50.5^{\circ} \mathrm{C}$. The activity of the enzymes was expressed as follows: $1 \mathrm{FPU}$ - enzyme dose releasing $1 \mu \mathrm{mol}$ glucose from Whatman filter paper No. 1 during $1 \mathrm{~min} ; 1 \mathrm{CBU}$ - enzyme dose converting $1 \mu \mathrm{mol}$ cellobiose to $2 \mu \mathrm{mol}$ glucose during $1 \mathrm{~min}$.

Fermentations of rye straw mashes and microcrystalline cellulose were conducted in a four-day system at a temperature of $37^{\circ} \mathrm{C}$. For this process, Saccharomyces cerevisiae Red star Ethanol Red (Lesaffe, Poland) yeast were used.

For comparison of the effect of the pretreatment on the cellulose structure and the yield of reducing sugars and bioethanol, control samples were prepared in the form of suspensions of cellulose and rye straw not subjected to the ionic liquid treatment. The experiment was conducted in three repetitions for each variant. The samples were analyzed in terms of total reducing sugars and ethyl alcohol content. 
Determination of total reducing sugar content after enzymatic hydrolysis was conducted using the colorimetric method utilizing the properties of reducing saccharides, which in alkaline environment reduce the nitro groups of 3,5-dinitrosalicylic acid to amino groups, exhibiting orange colour. Colour intensity proportional to the amount of reducing sugars constitutes a basis for quantitative analysis thereof (Ghose, 1987).

Determination of the ethanol content in post-fermentation mashes was conducted in order to control the fermentation processes using Saccharomyces cerevisiae Red Star Ethanol Red yeast. A cell test kit for determination of alcohol by R-Biopharm/BOEHRINGER MANNHEIM company was used.

\section{RESULTS AND DISCUSSION}

The average content of cellulose in rye straw was estimated at the level of $36.5 \pm 0.15 \%$, and the average Klason lignin content was $21.37 \pm 0.09 \%$. Klason lignin is defined as the mass of fraction that remains after hydrolysis of lignocellulosic material using sulfuric acid IV (Rodrigues et al., 1999). The dry matter of rye straw content was equal to $95.14 \pm 0.03 \%$. Evaluation of material properties also

T a b l e 1. Content of cellulose and Klason lignin in rye straw prior to and after the ionic liquid pretreatment

\begin{tabular}{lccc}
\hline & \multicolumn{3}{c}{ Content (\%) } \\
\cline { 2 - 4 } Type of material & cellulose & $\begin{array}{c}\text { Klason } \\
\text { lignin }\end{array}$ & dry matter \\
\hline Rye straw & $36.5 \pm 0.15$ & $21.3 \pm 0.09$ & $95.14 \pm 0.03$ \\
$\begin{array}{l}\text { Rye straw after } \\
\text { ionic liquid } \\
\text { pretreatment }\end{array}$ & $33.1 \pm 0.08$ & $9.3 \pm 0.11$ & $91.99 \pm 0.07$ \\
\hline
\end{tabular}

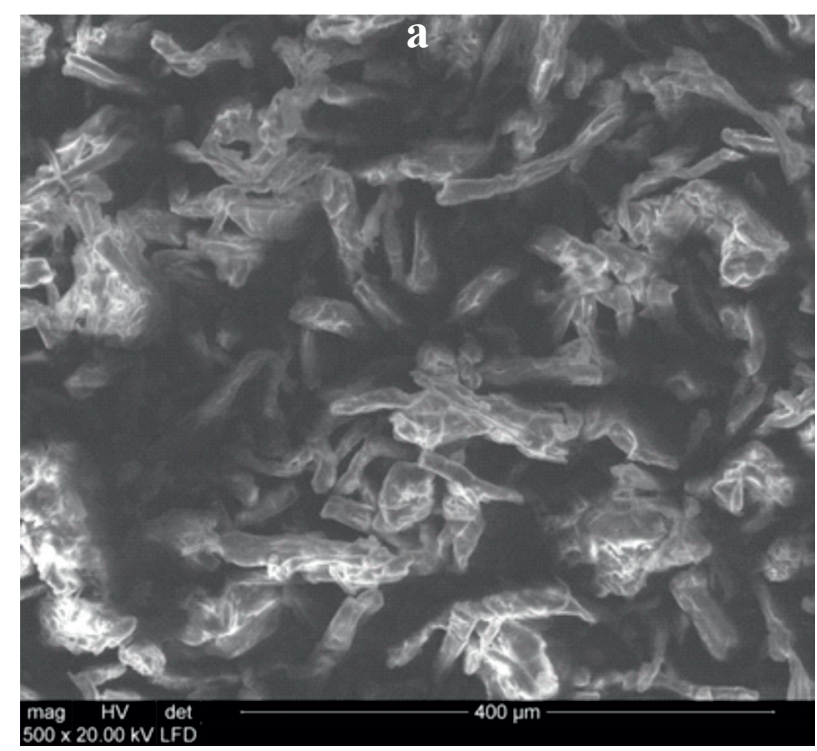

allowed assessment of the effect of the ionic liquid pretreatment of rye straw on the reduction of the lignin amount after the process. The differences in the content of cellulose and Klason lignin in the material under investigation prior to and after the pretreatment are shown in Table 1.

The lignin content in the straw samples after the pretreatment was lower in comparison to the control samples. The use of the ionic liquid resulted in the removal of over $52 \%$ lignin from the rye straw. Moreover, the content of cellulose in the samples changed after application of the pretreatment of the raw material. Most likely, this was caused by lower cellulose content in the input samples or partial loss of cellulosic fibres during the pretreatment.

The crystal structure of cellulose is considered one of the key factors limiting its susceptibility to hydrolysis. The high crystallinity of cellulose fibres restricts the access of cellulolytic enzymes to their interior and reduces the efficiency of hydrolysis.

Ionic liquid pretreatment reduces the degree of cellulose crystallinity and increases the amount of sites available for enzymes. The studies on the morphology of the cellulose fibre structure precipitated from the ionic liquid and native material were performed using a scanning electron microscope (SEM). Figure 1 show microscopic images of microcrystalline cellulose prior to and after the ionic liquid pretreatment. Microscopic observation shows that the structure of regenerated cellulose is characterized by a completely different morphology, compared to the initial cellulose.

After precipitation of the ionic liquid from the solution, the structure of both types of cellulosic materials such as microcrystalline cellulose and rye straw forms a more homogeneous material, which indicates a decline of a specific structure of the fibre cell wall after physical cellulose dissolution and transition into more a homogeneous macro-

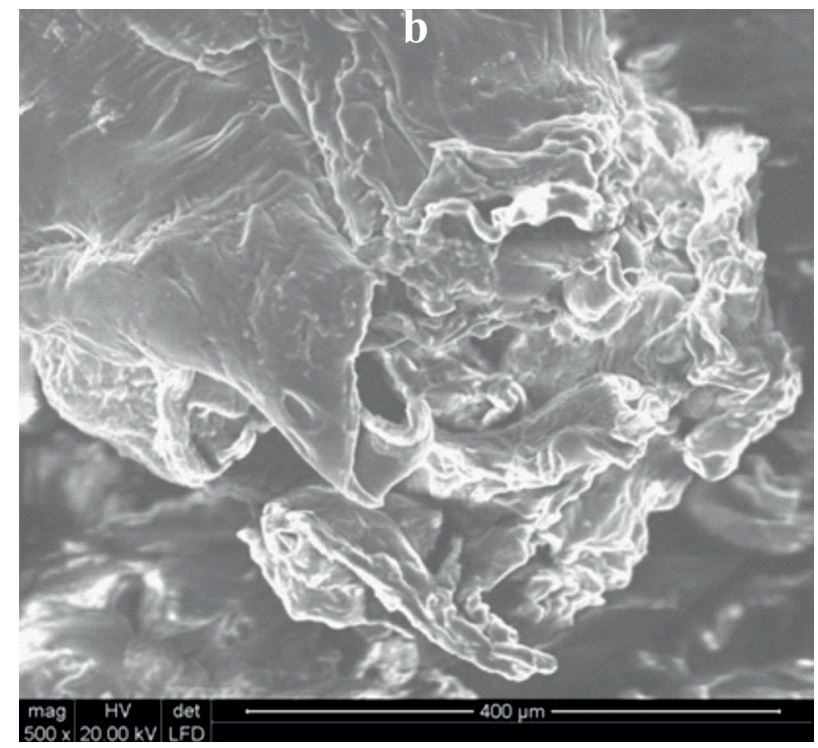

Fig. 1. SEM image of microcrystalline cellulose: $a$ - prior to, $b$ - after the ionic liquid pretreatment. 

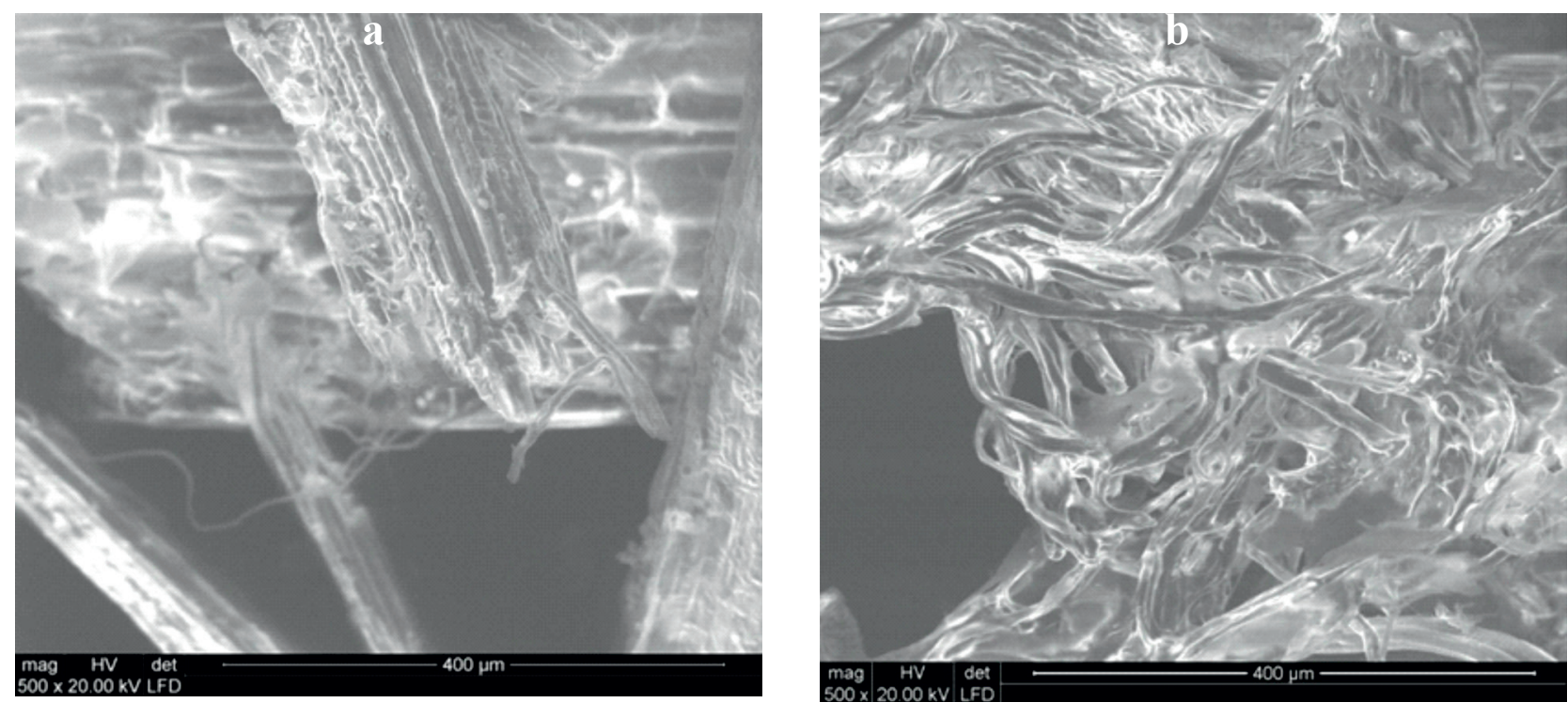

Fig. 2. SEM image of rye straw: $a$ - prior to, $b$ - after the ionic liquid pretreatment.

and microstructure (Fig. 2). Similar results were obtained by Moxley et al. (2008) and Surma-Ślusarska and Danielewicz (2012), who subjected cellulosic material to pretreatment using the ionic liquid.

With the use of scanning electron microscopy (SEM) and X-ray (XRD), Ang et al. (2012) analyzed structures of rice husks prior to and after pretreatment with the use of 1-ethyl-3-methylimidazolium acetate, 1-ethyl-3-methylimidazoliumphosphate, and 1-butyl-3-methylimidazolium chloride. They showed that, as a result of 1-ethyl-3-methylimidazolium acetate pretreatment, there was an increase in the number of termination sites in the polymer chains of the husk structure, compared to purified samples obtained for the two remaining ionic liquids.

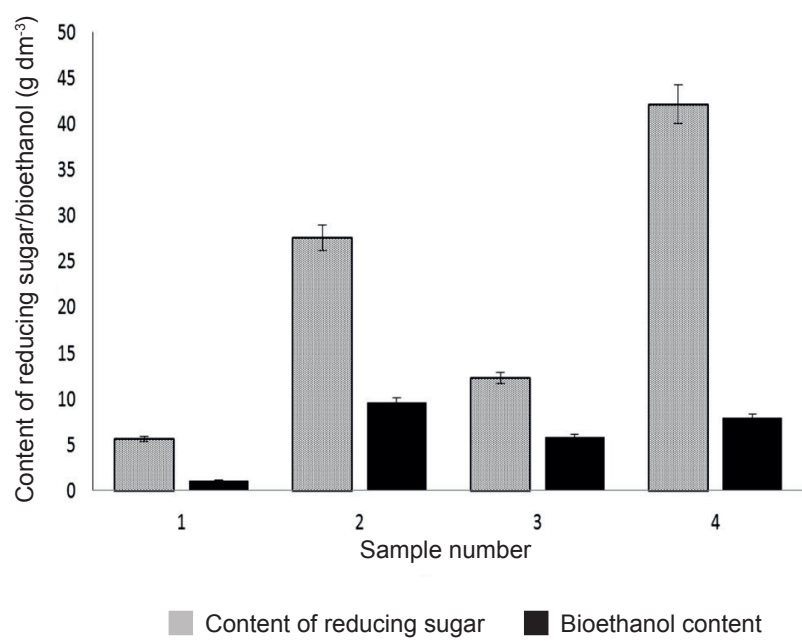

Fig. 3. The content of reducing sugars and ethanol in each sample: 1 - rye straw (control), 2 - rye straw after the ionic liquid pretreatment, 3 - microcrystalline cellulose (control), 4 - microcrystalline cellulose after the ionic liquid pretreatment.
Singh et al. (2009) visualized switchgrass dissolution in 1-ethyl-3-methylimidazolium acetate through confocal fluorescence images and found that the ionic liquid completely broke down the organized cell wall structure in $2 \mathrm{~h}$. Their analysis of SEM images of switchgrass before and after the pretreatment indicated that there was no lignin accumulation in pretreated and regenerated cellulose (Luo et al., 2013).

In the present studies, the effect of the ionic liquid treatment of cellulosic materials on the content of reducing sugars and ethyl alcohol after enzymatic hydrolysis and fermentation, respectively, was observed. The highest content of reducing sugars $\left(42.14 \mathrm{~g} \mathrm{dm}^{-3}\right)$ was found in a sample of microcrystalline cellulose treated with 1-ethyl-3-methylimidazolium acetate. The content of reducing sugars in a sample of rye straw purified with the ionic liquid $\left(27.54 \mathrm{~g} \mathrm{dm}^{-3}\right)$ was also at a high level (Fig. 3). Similar results were obtained by Fu and Mazza (2011), who purified wheat rye straw using an ionic liquid. The use of 1-ethyl-3-methylimidazolium acetate improved the yield of reducing sugars by $81 \%$ after enzymatic hydrolysis as compared to the control sample. Liu and Chen (2006) subjected wheat straw to regeneration with 1-butyl-3-methylimidazolium chloride. The authors showed that ionic liquid pretreatment affected depolymerisation of cellulose, increasing at the same time its susceptibility to enzymatic hydrolysis.

The use of the ionic liquid for purification of lignocellulosic materials affects the efficiency of enzymatic hydrolysis and the degree of cellulose degradation into simple sugars by cellulolytic enzymes. Reducing sugars resulting after enzymatic seizing of cellulosic solutions are substrates in the alcoholic fermentation process conducted using Saccharomyces cerevisiae Red Star Ethanol Red 
yeast. Bioconversion of fermentable sugars into ethanol was conducted for the samples of rye straw and microcrystalline cellulose, as well as the control samples of these materials. The highest concentration of ethanol was observed in rye straw sample, which was purified with the ionic liquid $-9.64 \mathrm{~g} \mathrm{dm}^{-3}$. For comparison, the content of ethyl alcohol in the control sample of rye straw was at the level of $1.13 \mathrm{~g} \mathrm{dm}^{-3}$ (Fig. 3). These differences may result from the fact that the rye straw hydrolysate purified with the ionic liquid was characterized by a higher concentration of reducing sugars, as well as lower lignin content, which block of the activity of yeast in mashes. In the untreated microcrystalline cellulose samples, the ethanol content was $5.8 \mathrm{~g} \mathrm{dm}^{-3}$, while the ionic liquid pretreatment of this material resulted in an increase in the ethanol content to $7.98 \mathrm{~g} \mathrm{dm}^{-3}$. This may be related to the type of the ionic liquid used for cellulose dissolution. 1-ethyl-3-methylimidazolium acetate is an ionic liquid most commonly used for dissolving the lignocellulose materials due to the ability of cellulose and lignin dissolution. It allows separation of lignin from cellulose and reduction of the degree of cellulose crystallinity. After dissolution of pure cellulose with 1-ethyl-3-methylimidazolium acetate, the solution exhibited high viscosity, which hampered the mixing process during hydrolysis and fermentation. Although the cellulolytic enzymes were characterized by higher potentiality of hydrolysis of cellulosic material, due to the gel-like compact solid of microcrystalline cellulose, the access for enzymes could be difficult. Saha et al. (2005) fermented wheat straw using Saccharomyces cerevisiae yeast. As a result of the experiments conducted, it was noted that the ethanol content was not dependent on the system of the fermentation process, but on the treatment method of the material prior to hydrolysis and fermentation. The effect of pretreatment of lignocellulosic material as well as different temperatures on the efficiency of alcoholic fermentation was also proved by Eisenhuber et al. (2013), who produced ethanol from different types of straw: wheat, rye, and corn. The ethyl alcohol content was dependent on the pretreatment temperature: the higher the temperature, the more bioethanol was obtained.

The results of this study evaluating the impact of pretreatment of cellulosic materials using the ionic liquid unequivocally confirm that a change in the supramolecular structure of cellulose was observed. Regenerated cellulose material was characterized by a different, more uniform micro- and macrostructure as well as a modified crystalline structure, compared to the non-pretreated material, which in further stages of the research influenced positively the course of enzymatic hydrolysis and alcoholic fermentation. The research findings presented in this paper expand the existing knowledge about the treatment and enzymatic hydrolysis of other types of biomass for energy production. They also provide valuable information for analyses of biomass markets and energy generation from renewable sources in view of environmental protection standards, which can be found in the works by Kowalski and Lelek (2011), Rosik-Dulewska et al. (2011), Sarkar et al. (2012), and Sanderson (2006).

\section{CONCLUSIONS}

1. Modification of the crystalline structure of cellulose using the ionic liquid for the pretreatment increases the production of bioethanol from rye straw.

2. The ionic liquid favourably affects the crystal structure of cellulose, causing its relaxation and increasing the number of sites available for cellulolytic enzymes in the chain of this polysaccharide.

3. 1-ethyl-3-methylimidazolium acetate partially separates lignin from the remaining components of rye straw and does not constitute a barrier for the activity of cellulolytic enzymes and yeast used in the studies.

4. The highest content of reducing sugars from the enzymatic hydrolysis was observed in the sample of microcrystalline cellulose that was purified with the ionic liquid.

5. The ethanol content was the highest in the sample of rye straw, which was purified with 1-ethyl-3-methylimidazolium acetate prior to the hydrolysis and fermentation processes.

\section{REFERENCES}

Ang T.N., Ngoh G.Ch., Chua A.S.M., and Lee M.G., 2012. Elucidation of the effect of ionic liquid pretreatment on rice husk via structural analyses. Biotechnology Biofuels, 5(1), 67, doi: 10.1186/1754-6834-5-67.

Betiku E. and Taiwo Abiola E., 2015. Modeling and optimization of bioethanol production from breadfruit starch hydrolyzate vis-à-vis response surface methodology and artificial neural network. Renewable Energy, 74, 87-94.

Brandt A., Erickson J.K., Hallett J.P., Murphy R.J., Potthast A., Ray M.J., Rosenau T., Schrems M., and Welton T., 2012. Soaking of pine wood chips with ionic liquids for reduced energy input during grinding. Green Chemistry, 14 1079-1085.

Bučko J., Jabłoński M., Košiková B., and Nicewicz D., 2012. Biotechnology and Using Dendromass (in Polish). SGGW Press, Warsaw, Poland.

Cheng J. and Timilsina G.R., 2011. Status and barriers of advanced biofuel technologies: A review. Renewable Energy, $12,36,3541-3549$.

Eisenhuber K., Jäger A., Wimberger J., and Kahr H., 2013. Comparison of different pretreatment methods for straw for lignocellulosic bioethanol production. Agronomy Res., 11(1), 173-182.

Fu D. and Mazza G., 2011. Aqueous ionic liquid pretreatment of straw. Bioresource Technology, 102(13), 7008-7011.

Gąsiorek E. and Wilk W., 2011. Possibilities of utilizing the solid by-products of biodiesel production - a review. Polish J. Chemical Technol., 13(1), 58-62.

Ghose T.K., 1987. Measurement of cellulase activities. Pure Applied Chemistry, 59(2), 257-268. 
Han M., Kim Y., Kim Y., Chung B., and Choi G.-W., 2011. Bioethanol production from optimized pretreatment of cassava stem. Korean J. Chemical Eng., 1(28), 119-125.

Kowalski Z. and Lelek L., 2011. Modeling of Biomass Market in Malopolska Region Including Legal, Market and Environmental Aspects (in Polish). Annual Set The Environment Protection, 13, 1429-1440.

Krutul D., 2002. Wood Chemistry Exercises and Selected Aspects of Organic Chemistry (in Polish). SGGW Press, Warsaw, Poland.

Li M.F., Fan Y.M., Xu F., Sun R.C., and Zhang X.L., 2010. Cold sodium hydroxide/urea based preatreatment of bamboo for bioethanol production: characterization of the cellulose rich fraction. Industrial Crops Products, 32, 551-9.

Liu L. and Chen H., 2006. Enzymatic hydrolysis of cellulose materials treated with ionic liquid [BMIM]Cl. Chinese Science Bulletin, 51(20), 2432-2436.

Luo J., Cai M., and Gu T., 2013. Pretreatment of lignocellulosic biomass using green ionic liquids. Green Biomass Pretreatment Biofuels Production, 6, 127-153.

Lutomski K., 2002. Research methods of wood protection chemicals and their application in technology (in Polish). Agricultural Academy Press), Poznań, Poland.

McKendry P., 2002. Energy production from biomass (Part 2): conversion technologies. Bioresources Technol., 83(1), 47-54.

Moxley G., Zhu Z., and Zhang P., 2008. Efficienty Sugar Release by the Cellulose Solvent-Based Lignocellulose Fractionation Technology and Enzymatic Cellulose Hydrolysis. J. Agric. Food Chemistry, 56(17), 7885-90.

Neelakandan T. and Usharani G., 2009. Optimization and production of bioethanol from cashew apple juice using immobilized yeast cells by Saccharomyces cerevisiae. America-Eurasian J. Scientific Res., 4(2), 85-88.

Pulidindi I.N., Kimchi B.B., and Gedanken A., 2014. Can cellulose be a sustainable feedstock for bioethanol production? Renewable Energy, 71, 77-80.

Rodrigues J., Faix O., and Pereira H., 1999. Improvement of the acetylbromide method for lignin determination within large scale screening programmes. Holz als Roh- und Werkstoff, 57(5), 341-345.

Rosik-Dulewska C., Karwaczyńska U., and Ciesielczyk T., 2011. Possibilities of utilisation of organic and mineral waste according to rules of environment protection (in Polish). Annual Set The Environment Protection, 13, 361-376.

Saha C.B., Iten L.B., Cotta M.A., Victor Wu Y., 2005. Dilute acid pretreatment, enzymatic saccharification and fermentation of wheat straw to ethanol. Process Biochemistry, 40(12), 3693-3700.

Sanderson K.W., 2006. Are ethanol and other biofuel technologies part of the answer for energy independence? Cereal-Foods-World, 52, 5-7.

Sarkar N., Ghosh S.K., Bannerjee S., and Aikat K., 2012. Bioethanol production from agricultural wastes: An overview. Renewable Energy, 1(37), 19-27.

Sathitsuksanoh N., George A., and Zhangy-H.P., 2012. New lignocellulose pretreatments using cellulose solvents: a review. J. Chemistry Technol. Biotechnol., Wiley Library, doi:10.1002/jctb.3959

Shill K., Padmanabhan S., Xin Q., Prausnitz J.M., Clark D.S., and Blanch H.W., 2010. Ionic liquid pretreatment of cellulosic biomass: enzymatic hydrolysis and ionic liquid recycle. Biotechnology Bioeng., 108(3), 511-520.

Singh S., Simmons B.A., and Vogel K.P., 2009. Visulization of biomass solubilization and cellulose regeneration during ionic liquid pretreatment of switchgrass. Biotechnology Bioenergy, 104, 68-75.

Surma-Ślusarska B. and Danielewicz D., 2012. Solubility of various types of cellulose in ionic liquids (in Polish). Przegląd Papierniczy, 68, 43-49.

Surmiński J., 2006. Outline of wood chemistry (in Polish). Agricultural Academy Press, Poznań, Poland.

Szymanowska-Powałowska D., Lewandowicz G., Kubiak P., and Blaszczak W., 2014. Stability of the process of simultaneous saccharification and fermentation of corn flour. The effect structural changes of starch by stillage recycling and scaling up of the process. Fuel, 119, 328-334.

Wang M.J., Tan J.X., Sun J.F., and Mou J.L., 2011. Optimization of ethanol from sweet sorghum juice using response surface methodology. Energy Sources, 33(12), 1139-46.

Zhu S., Yu P., Lei M., Tong Y., Zheng L., Hang R., Ji J., Chen Q., and Wu Y., 2013. Investigation of the toxicity of the ionic liquid 1-butyl-3-methylimidazolium chloride to Saccharomyces cerevisiae AY93161 for lignocellulosic ethanol production. Polish J. Chemical Technol., 15(2), 94-98. 